\title{
Hemşirelik Öğrencilerinin Mesleki Değerleri ile Hemşirelik Tanılarını Algılamaları Arasındaki İlişki
}

\author{
Serpil SU ${ }^{1}$ (D) Kübra Nur KÖSE ${ }^{2}$ \\ ${ }^{1}$ Necmettin Erbakan Üniversitesi, Hemşirelik Fakültesi, Hemşirelik Bölümü, Konya, Türkiye, suserpil@ gmail.com \\ ${ }^{2}$ Necmettin Erbakan Üniversitesi, Hemşirelik Fakültesi, Hemşirelik Bölümü, Konya, Türkiye, \\ kubranurkosee@ hotmail.com (Corresponding Author/Sorumlu Yazar)
}

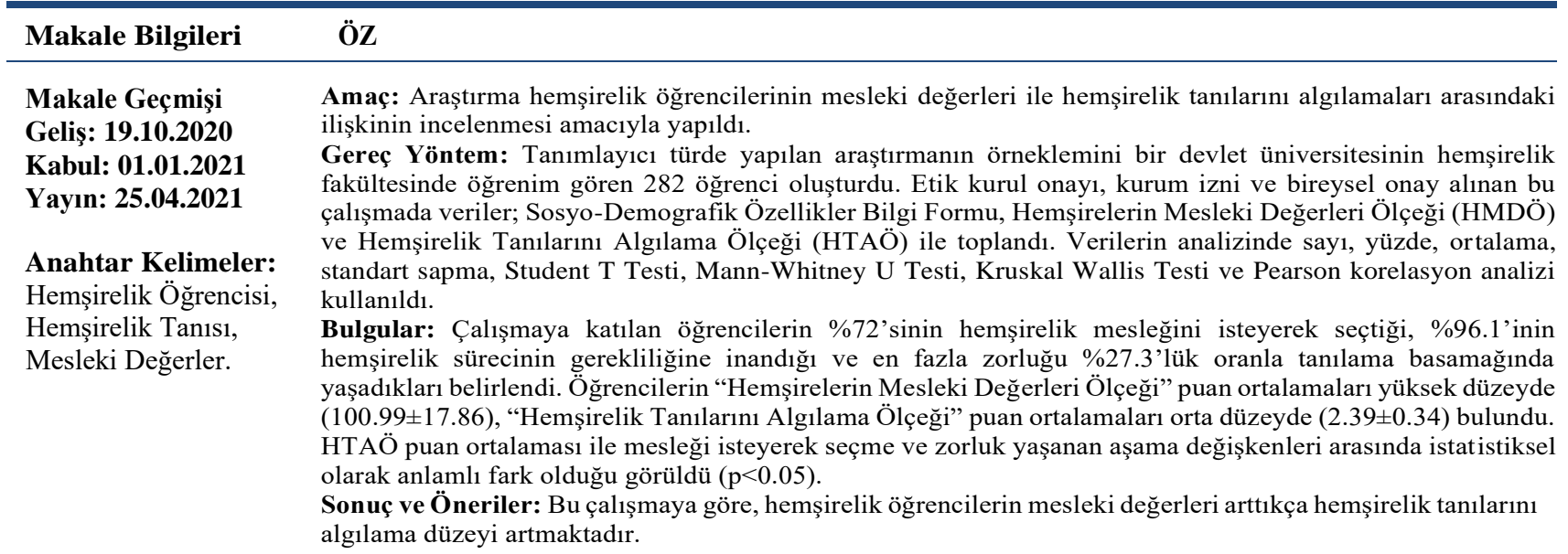

\section{Investigate The Relationship Between Nursing Students'}

\section{Professional Values and Perception of Nursing Diagnosis}

\begin{tabular}{|c|c|}
\hline Article Info & ABSTRACT \\
\hline $\begin{array}{l}\text { Article History } \\
\text { Received: } 19.10 .2020 \\
\text { Accepted: } 01.01 .2021 \\
\text { Published: } 25.04 .2021\end{array}$ & $\begin{array}{l}\text { Purpose: The study was conducted to investigate the relationship between nursing students' professional values } \\
\text { and perception of nursing diagnosis. } \\
\text { Method: The sample of this descriptive study consisted of } 282 \text { students in the nursing department of a state } \\
\text { university in Turkey. Ethical approval, institunioal approval and individual approval were obtained. Data was } \\
\text { collected with Socio-Demographic Characteristics Questionnaire, Nurses Professional Values Scale (NPVS) } \\
\text { and Nursing Diagnoses Perception Scale (NDPS). Number, percentage, standard deviation, Student T test, } \\
\text { Mann-Whitney U test, Kruskal Wallis Test and Pearson correlation analysis were used to analyse the data. } \\
\text { Results: In the study } 72 \% \text { of the students reported that they willingly chose nursing as a profession, } 96.1 \% \\
\text { reported that they believe that nursing process is necessary and they experienced the biggest difficulty in the } \\
\text { diagnosis stage with } 27.3 \% \text {. The students' mean score in the "Nurses Professional Values Scale was high } \\
\text { (100.99 } \pm 17.86) \text {, and in the "Nursing Diagnoses Perception Scale" was at moderate level ( } 2.39 \pm 0.34) \text {. There } \\
\text { was a statistically significant difference between NDPS mean score and the variables of willingly choosing } \\
\text { nursing as a career and the stage they experience difficulty (p<0.05). There was a positive statistically highly } \\
\text { significant relationship between NPVS and BDPS scores of the students (p<0.001). } \\
\text { Conclusion and Suggestions: The study found that as nursing students' professional values increase, their }\end{array}$ \\
\hline
\end{tabular}

Atıf/Citation: Su, S., \& Köse, K.N. (2021). Hemşirelik öğrencilerinin mesleki değerleri ile hemşirelik tanılarını algılamaları arasındaki ilişki. Genel Sağlık Bilimleri Dergisi, 3(1), 20-28.

"This article is licensed under a Creative Commons Attribution-NonCommercial 4.0 International License (CC BY-NC 4.0)" 


\section{GİRIŞ}

Mesleki değerler, bireylerin mesleki görevlerini yerine getirirken uygulaması gereken davranış, inanç ya da rehber ilkeler olarak tanımlanmaktadır (Dündar vd., 2019). Hemşirelik uygulamalarının temelini oluşturan mesleki değerler hemşirelerin düşüncelerine, eylemlerine, uygulamalarına ve hastalarla etkileşimlerine rehberlik eden en önemli unsurlardan birisidir (Moon vd., 2014; Çöplü ve Tekinsoy Kartın, 2018). Özgecilik, eşitlik, insan onuru, sosyal adalet, estetik, özgürlük ve doğruluk hemşirelik mesleğine ait temel değerlerdir (Kaya vd., 2012; Karadağl1 2016; Paslı Gürdoğan vd., 2018). Hemşireler sağlıklı/hasta bireye bakım verirken, etik ikilemlerle ilgili karar alırken ve hemşirelik sürecini uygularken bu mesleki değerlerini kullanmaktadırlar (Kaya vd., 2010). Mesleki değerleri benimseyen hemşireler hasta problemlerinin çözümlenmesi ve öncelikli eylemlerin belirlenmesi yeterliği kazanarak hemşirelik sürecini etkin bir şekilde kullanır ve kaliteli bir bakım sunulmasını sağlar (Zengin vd., 2018; Olmaz ve Karakurt, 2019).

Hemşirelik süreci; sağlıklı/hasta bireyin yaşamın başlangıcından sonuna kadar sağlık bakımı ihtiyaçlarının saptanması ve bireye özgü bakım verilmesinde kullanılan sistematik, bilimsel ve planlı bir sorun çözme yöntemidir (Birol 2000; Kaya vd., 2010; Yıldırım ve Özkahraman Koç, 2013). Veri toplama, hemşirelik tanısını belirleme, planlanma, uygulama ve değerlendirme olmak üzere beş aşamadan oluşmaktadır (Birol 2000; Yıldırım ve Özkahraman Koç, 2013; Uysal vd., 2016). Hemşirelik sürecinin en temel ögesi olan hemşirelik tanıları Amerikan Hemşirelik Tanıları Birliği'ne (NANDA-I, North American Nursing Diagnosis Association) göre "bir birey, aile ya da toplumun mevcut ya da olası sağlık problemlerine/yaşam süreçlerine tepkileri hakkında hemşire tarafından verilen klinik bir karar/ yargı" olarak tanımlanmaktadır (Akın Korhan vd., 2015; NANDA-I 2019). Hemşirelik tanıları hemşirelerin klinik değerlendirmeler, görüşmeler ve gözlemlerini kullanarak hastanın sağlı problemlerine verdiği cevabı analiz etmesine yardımcı olmaktadır (Akın Korhan vd., 2015). Doğru hemşirelik tanıları saptamak hastaların daha iyi hemşirelik bakımı alabilmesini sağlamaktadır (Uysal vd., 2016). Bu doğrultuda ülkemizde hemşirelik eğitimi veren tüm okullarda hemşirelik süreci hem teorik, hem de uygulamalı olarak anlatılmaktadır (Akansel ve Palloş, 2020).

Hemşirelik süreci, hemşirelik öğrencilerine gereken bilgi ve beceriyi kazandırarak sağlıklı ya da hasta bireyin hemşirelik bakım ihtiyaçlarını belirleyebilen, hemşirelik bakımını planlayabilen, uygulayabilen ve değerlendirebilen hemşireler yetiştirilmesini sağlamaktadır (Kaya ve vd., 2010; Orkun ve Çınar Yücel, 2017). Ancak yapılan çalışmalarda öğrencilerin hemşirelik süreci ile ilgili zorluk yaşadığı ve en çok zorluğu hemşirelik tanısının belirlenmesi aşamasında yaşadıkları belirtilmektedir (Uysal vd., 2016). Hemşirelik öğrencilerinin hemşirelik tanılarını belirleyebilme düzeyleri hakkında yapılan bir çalışmada; öğrencilerin, etiyolojik faktörlerle birlikte tanıyı doğru belirleyebilen öğrenci oranının düşük düzeyde olduğu saptanmıştır (Güner ve Terakye, 2000). Keski ve Karadağ (2010) ve Sü (2017)'nün yaptıkları çalışmalarda ise öğrencilerin hemşirelik tanılarını belirlemede sorun yaşadı̆̆ı bulunmuştur. Yine başka bir çalışmada; öğrencilerin hemşirelik tanılarını yetersiz verilere dayanılarak belirlediği, tıbbi tanı, belirti ve bulguların hemşirelik tanısı olarak ifade edildiği belirlenmiştir (Uysal vd., 2016).

Mesleki değerler hemşirelik öğrencilerinin eleştirel düşünme yeteneklerini geliştirerek doğru hemşirelik süreci uygulamasında rehberlik etmektedir (Yıldırım ve Özkahraman Koç, 2013; H. Kaya vd., 2017). Bu konudaki literatür incelendiğinde hemşirelik öğrencilerinin mesleki değerleri (Lin ve Wang, 2010; Lacobucci vd., 2013; Arkan vd., 2019; Caner vd., 2019) ile hemşirelik tanılarını algılamalarını (Karaca ve Aslan, 2018) ayrı ayrı inceleyen çalışmalar olmasına karşın, birlikte inceleyen çalışmaya rastlanmamıştır. Bu nedenle bu çalışmada hemşirelik öğrencilerinin mesleki değerleri ile hemşirelik tanılarını algılamaları arasındaki ilişkinin incelenmesi amaçlandi.

\section{Araştırma Soruları}

1. Hemşirelik öğrencilerinin mesleki değerler düzeyi nedir?

2. Hemşirelik öğrencilerinin hemşirelik tanılarını algılama düzeyi nedir? 
3. Hemşirelik öğrencilerinin sosyodemografik özellikleri mesleki değerler düzeyini ve hemşirelik tanılarını algılama düzeyini etkiler mi?

4. Hemşirelik öğrencilerinin mesleki değerleri ile hemşirelik tanılarını algılamaları arasında ilişki var midir?

\section{YÖNTEM}

\section{Araştırmanın Tipi}

Araştırma tanımlayıcı olarak yapıldı.

\section{Evren ve Örneklem}

Hemşirelik fakültesinde öğrenim görmekte olan tüm öğrenciler $(\mathrm{N}=550)$ evreni oluşturdu. Araştırmada örneklem seçimine gidilmedi, verilerin toplandığı tarihte devamsız olmayan ve araştırmaya katılmaya gönüllü olan öğrenciler örnekleme alındı (n:282).

\section{Veri Toplama Araçları}

Araştırmanın verileri 01-31 Mayıs 2019 tarihleri arasında Öğrenci Bilgi Formu, Hemşirelerin Mesleki Değerleri Ölçeği (HMDÖ) ve Hemşirelik Tanılarını Algılama Ölçeği (HTAÖ) kullanılarak toplandı.

\section{Ö̆̆renci Bilgi Formu}

Araştırmacılar tarafından literatür doğrultusunda (Kaya vd., 2011; Göriş vd., 2014; Karadağlı 2016; Arkan vd., 2019) oluşturulan formda yaş, cinsiyet, sınıf, mesleği isteyerek seçme, hemşirelik sürecinin gerekliliğine inanma ve en çok zorluk yaşanan basamağın sorgulandığı toplam altı soru yer aldı.

\section{Hemşirelerin Mesleki Değerleri Ölçeği (HMDÖ)}

Weis ve Schank tarafından ölçek 2009 yılında geliştirilmiştir. Türkiye' de Geçkil ve diğerleri tarafından 2012 yılında geçerlilik ve güvenirliği yapılmıştır. Hemşirelerin mesleki değerlerini kendilerinin değerlendirdikleri bu ölçek 26 maddeden oluşan beşli likert tipi bir ölçektir. Ölçekteki her bir ifade 'çok önemlidir 'den ‘önemli değildir' şeklinde sıralanmakta ve her bir kategori 1, 2, 3, 4, 5 olarak puanlanmaktadır. Ölçekten alınabilecek en düşük puan 26, en yüksek puan ise 130'dur. Yüksek puanlar yüksek mesleki değerleri göstermektedir. Ölçeğin toplam Chronbach Alpha değeri 0.92 bulunmuştur (Geçkil vd, 2012).

\section{Hemşirelik Tanılarını Algılama Ölçeği (HTAÖ)}

Olsen, Frost ve Orth tarafından 1991 yılında geliştirilen Hemşirelik Tanılarını Algılama Ölçeği (Perceptions of Nursing Diagnoses Survey), hemşirelerin hemşirelik tanılarını algılama durumlarını belirlemek amacıyla geliştirilmiştir. Akın Korhan ve diğerleri tarafından 2013 yılında Türk toplumuna uyarlanmıştır. Ölçek hemşirelik tanılarının kullanımı, kullanışlılığı, amaçları, sonuçları, hedefleri ve sınırlı1ıkları konusunda hemşirelerin algılamalarını yansıtan ifadelerden oluşmaktadır. Ölçek 1 (tamamen katılıyorum) ile 5 (tamamen katılmıyorum) arasında değişen ve 26 madde içeren beşli likert tiptedir. Ölçekten alınan toplam puan minumum 1, maksimum 5'tir. Ölçekten alınan toplam puanın düşük olması hemşireler tarafından hemşirelik tanılarının pozitif yönde algılandığını ifade etmektedir. Orjinal ölçeğin toplam Cronbach alfa değeri 0.94 olarak bulunmuştur (Korhan vd., 2013).

\section{Verilerin Toplanması}

Araştırmanın verileri toplanmadan önce veri toplama formunun anlaşılırlığını değerlendirmek için 10 öğrenciye ön uygulama yapıldı ve anlaşı1ır olduğu belirlendi. Verilerin toplandığı gün katılımcılara araştırma hakkında bilgi verilerek sözel onay alındı ve arkasından veri formları doldurmaları için dağıtıldı. Formun doldurulması 15-20 dakikalık sürede tamamlandı. 


\section{Etik Boyut}

Araştırmaya başlamadan önce bir devlet üniversitesi tıp fakültesi ilaç ve tıbbi cihaz dışı araştırmalar etik kurulundan etik kurul onayı (2019/1861), kurum izni ve katılımcılardan sözel onam alındı. Ayrıca Hemşirelik Tanılarını Algılama Ölçeği (HTAÖ) ve Hemşirelerin Mesleki Değerleri Ölçeği (HMDÖ)'ni kullanmak amacıyla yazarlardan e-mail yoluyla izin alındı.

\section{Verilerin Değerlendirilmesi}

Araştırmanın verileri bilgisayar ortamına aktarıldıktan sayı, yüzde, ortalama, standart sapma, Student T Testi, Mann-Whitney U Testi, Kruskal Wallis Testi ve Pearson Korelasyon Testi kullanılarak analiz edildi.

\section{BULGULAR}

Çalışmaya katılan öğrencilerin \%80.5'inin kadın olduğu, \%25.2'sinin üçüncü sınıfta öğrenim gördüğü, \%72'sinin hemşirelik mesleğini isteyerek seçtiği, \%96.1'inin hemşirelik sürecinin gerekliliğine inandığı ve en fazla zorluğu \%27.3'lük oranla tanılama basamağında yaşadıkları belirlendi (Tablo 1).

Tablo 1. Öğrencilerin Sosyodemografik Özellikleri $(n=282)$

\begin{tabular}{lcc}
\hline Özellikler & $\mathbf{n}$ & $\mathbf{\%}$ \\
\hline Cinsiyet & 227 & 80.5 \\
Kadın & 55 & 19.5 \\
Erkek & & 32.3 \\
\hline Sinıf & 91 & 23.8 \\
\hline 1. sınıf & 67 & 25.2 \\
2. sınıf & 71 & 18.8 \\
3. sınıf & 53 & \\
4. sinıf & & 72.0 \\
\hline Mesleği İsteyerek Seçme & 203 & 28.0 \\
Mesleği isteyerek seçen & 79 & \\
Mesleği isteyerek seçmeyen & & 96.1 \\
\hline Hemşirelik Sürecinin Gerekliliğine İnanma & 271 & 3.9 \\
Gerekliliğine inanan & 11 & 26.2 \\
Gerekliliğine inanmayan & & 27.3 \\
\hline Zorluk Yaşanan Aşama & 74 & 21.3 \\
Veri toplama & 77 & 16.7 \\
Tanılama & 60 & 8.5 \\
Planlama & 47 & $\mathbf{1 0 0}$ \\
Uygulama & 24 & \\
\hline Değerlendirme & $\mathbf{2 8 2}$ & \\
\hline
\end{tabular}

Öğrencilerin HMDÖ ve HTAÖ'nden aldıkları puan ortalamaları Tablo 2'de verildi. Öğrencilerin HMDÖ'nden aldıkları puan ortalaması 100.99 \pm 17.86 , HTAÖ'den aldıkları puan ortalaması ise $2.39 \pm 0.34$ olarak bulundu (Tablo 2).

Tablo 2. Öğrencilerin HMDÖ ve HTAÖ Puan Ortalamaları (n=282)

\begin{tabular}{llll}
\hline Ölçekler ve Alt Boyutları & Alınabilecek Min.-Max. Puan & Alınan Min.-Max. Puan & $\mathbf{X} \pm$ SS \\
\hline Bakım Verme & $8-40$ & $8-40$ & $32.86 \pm 6.23$ \\
Profesyonellik & $7-35$ & $9-28$ & $18.96 \pm 3.26$ \\
Aktivizm & $5-25$ & $5-25$ & $19.33 \pm 3.85$ \\
Adalet & $3-15$ & $3-15$ & $11.76 \pm 2.32$ \\
Sadakat & $3-15$ & $3-15$ & $11.21 \pm 2.54$ \\
HDPÖ Toplam & $\mathbf{2 6 - 1 3 0}$ & $\mathbf{2 6 - 1 3 0}$ & $\mathbf{1 0 0 . 9 9 \pm 1 7 . 8 6}$
\end{tabular}




\begin{tabular}{lccc}
\hline $\begin{array}{l}\text { Hemşirelik mesleğinin tanımı ve } \\
\text { tanıtımı }\end{array}$ & $1-5$ & $1.00-4.08$ & $1.90 \pm 0.55$ \\
$\begin{array}{l}\text { Hastanın durumunu açık bir şekilde } \\
\text { tanımlama }\end{array}$ & $1-5$ & $1.00-5.00$ & $3.09 \pm 0.65$ \\
Kullanım kolaylığı & $1-5$ & $1.00-4.50$ & $2.67 \pm 0,59$ \\
Kavramsal yön & $1-5$ & $1.25-4.25$ & $2.83 \pm 0.57$ \\
HTAÖ Toplam & $\mathbf{1 - 5}$ & $\mathbf{1 . 4 6 - 3 . 4 6}$ & $\mathbf{2 . 3 9} \pm \mathbf{0 . 3 4}$ \\
\hline
\end{tabular}

Araştırmada öğrencilerin HMDÖ puan ortalaması ile yaş, cinsiyet, sınıf, hemşirelik sürecinin gerekliliğini inanma, mesleği isteyerek seçme ve zorluk yaşanan aşama değişkenleri arasında istatistiksel olarak anlamlı bir fark saptanmadı $(\mathrm{p}<0.05)$ (Tablo 3$)$.

Öğrencilerin HTAÖ puan ortalaması ile yaş, cinsiyet, sınıf, hemşirelik sürecinin gerekliliğini inanma değişkenliği arasında anlamlı bir fark bulunmaz iken, mesleği isteyerek seçme ve zorluk yaşanan aşama değişkenleri arasında istatistiksel olarak anlamlı fark olduğu görüldü $(\mathrm{p}<0.05)$ (Tablo 3$)$.

Araştırmada öğrencilerin HMDÖ ile HTAÖ puan ortalamaları arasında istatistiksel olarak pozitif yönde ileri düzeyde anlamlı bir ilişki olduğu belirlendi (Tablo 4).

Tablo 3. Öğrencilerin Sosyodemografik Özellikleri İle HMDÖ ve HTAÖ Puan Ortalamalarının Dağılımı

\begin{tabular}{|c|c|c|c|c|}
\hline & HMDÖ & & HTAÖ & \\
\hline Özellikler & $\mathbf{X} \pm \mathbf{S S}$ & Test ve $P$ değeri & $\mathrm{X} \pm \mathrm{SS}$ & Test ve $P$ değeri \\
\hline \multicolumn{5}{|l|}{ Yaş (yıl) } \\
\hline$\leq 21$ & $100.84 \pm 18.04$ & $\mathrm{t}=-0.221$ & $2.39 \pm 0.35$ & $\mathrm{t}=-0.108$ \\
\hline$\geq 22$ & $101.37 \pm 17.47$ & $\mathrm{P}=0.825$ & $2.40 \pm 0.32$ & $\mathrm{P}=0.914$ \\
\hline \multicolumn{5}{|l|}{$\overline{\text { Cinsiyet }}$} \\
\hline Kadın & $101.77 \pm 17.29$ & $\mathrm{t}=1.498$ & $2.39 \pm 0.33$ & $\mathrm{t}=0.015$ \\
\hline Erkek & $97.76 \pm 19.89$ & $\mathrm{P}=0.135$ & $2.39 \pm 0.36$ & $\mathrm{P}=0.988$ \\
\hline \multicolumn{5}{|l|}{ Sinıf } \\
\hline 1. sinif & $97.84 \pm 19.00$ & & $2.35 \pm 0.36$ & \\
\hline 2. sinif & $102.40 \pm 16.99$ & & $2.45 \pm 0.32$ & \\
\hline 3. sinif & $101.15 \pm 16.62$ & $\mathrm{~F}=1.737$ & $2.37 \pm 0.33$ & $\mathrm{~F}=1.242$ \\
\hline 4. $\sin 1 f$ & $104.39 \pm 18.12$ & $\mathrm{P}=0.160$ & $2.42 \pm 0.34$ & $\mathrm{P}=0.295$ \\
\hline \multicolumn{5}{|c|}{ Mesleği İsteyerek Seçme } \\
\hline Evet & $101.95 \pm 18.29$ & $\mathrm{t}=1.446$ & $2.37 \pm 0.33$ & $\mathrm{t}=-1.978$ \\
\hline Hayır & $98.53 \pm 16.57$ & $\mathrm{P}=0.149$ & $2.46 \pm 0.36$ & $P=0.049$ \\
\hline \multicolumn{5}{|c|}{$\begin{array}{l}\text { Hemşirelik Sürecinin Gerekliliğine } \\
\text { İnanma }\end{array}$} \\
\hline Evet & $101.22 \pm 17.86$ & $\mathrm{U}=1165.0$ & $2.39 \pm 0.34$ & $\mathrm{U}=937.5$ \\
\hline Hayır & $95.27 \pm 17.54$ & $\mathrm{P}=0.219$ & $2.58 \pm 0.39$ & $P=0.037$ \\
\hline \multicolumn{5}{|c|}{ Zorluk Yaşanan Aşama } \\
\hline Veri toplama & $102.12 \pm 18.36$ & & $2.45 \pm 0,32$ & \\
\hline Tanilama & $100.24 \pm 15.80$ & & $2.43 \pm 0,38$ & \\
\hline Planlama & $97.61 \pm 18.63$ & & $2.29 \pm 0,30$ & \\
\hline Uygulama & $102.93 \pm 18.95$ & $\mathrm{KW}=3.343$ & $2.44 \pm 0,30$ & $\mathrm{KW}=13.603$ \\
\hline Değerlendirme & $104.54 \pm 18.36$ & $\mathrm{P}=0.502$ & $2.26 \pm 0.31$ & $\mathbf{P}=\mathbf{0 . 0 0 9}$ \\
\hline Toplam & & & & \\
\hline
\end{tabular}

Tablo 4. Öğrencilerin HMDÖ ve HTAÖ Puan Ortalamaları Arasındaki İlişki

\begin{tabular}{lcc}
\hline & HTAÖ & p \\
\hline HMDÖ & $\mathbf{r}$ & 0.000 \\
\hline Bakim verme & -0.223 & 0.003 \\
\hline Profesyonellik & -0.174 & 0.000 \\
\hline Aktivizm & 0.637 & 0.006 \\
\hline Adalet & -0.162 & 0.005 \\
\hline Sadakat & -0.168 & 0.000 \\
\hline
\end{tabular}

$\mathrm{r}=$ Pearson Korelasyon Analiz 


\section{TARTIŞMA}

Hemşirelik öğrencilerinin mesleki değerlerle hemşirelik tanılarını algılamaları arasındaki ilişkiyi belirlemek amacıyla yaptığımız bu çalışmada ölçekten alınabilecek en yüksek puanın 130 olduğu dikkate alındığında öğrencilerin mesleki değerlerinin yüksek düzeyde olduğu saptanmıştır. Benzer olarak Lin ve Wang (2010)

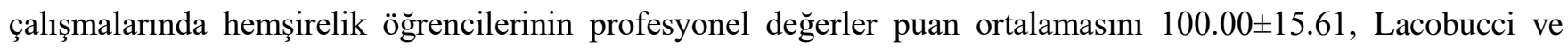

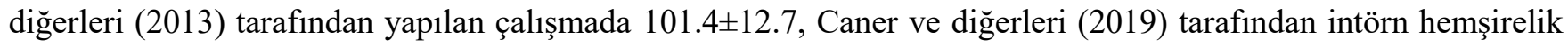
öğrencileri ile yapılan çalışmada 100.53 \pm 15.80 , Arkan ve diğerleri (2019) tarafından yapılan çalışmada $105.36 \pm$ 14.24, Kundakçı ve diğerleri (2018) son sınıf hemşirelik öğrencileri ile yaptığı çalışmada puan ortalaması 102.88 \pm 15.67 olarak saptanmıştır. Geçkil ve diğerleri (2012) yaptıkları çalışmada ise profesyonel değerler puan

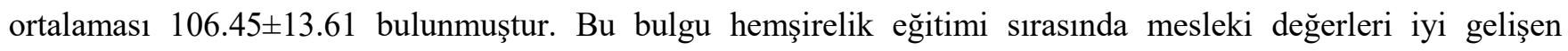
öğrencilerin mezun olduktan sonra bunu hasta bakımına yansıtacakları yönünde olumlu değerlendirilebilir.

Çalışmamızda hemşirelik öğrencilerinin hemşirelik tanılarını algılamaları puan ortalaması orta düzeyde bulunmuştur. Literatürde hemşirelik öğrencilerinin hemşirelik tanılarını algılaması ile ilgili sınırlı sayıda çalışmaya rastlanmıştır. Bizim çalışmamıza benzer şekilde Karaca ve Aslan (2018) tarafindan yapılan çalışmada hemşirelik tanılarını algılamaları puan ortalaması $2.44 \pm 0.44$, Halverson ve diğerleri (2011)'nin çalışmasında $3.09 \pm 0.63$ olarak bulmuşlardır. Erden ve diğerleri (2018)'nin çalışmasında ise öğrencilerin saptadıkları hemşirelik tanıların daha kolay belirlenen fizyolojik alana odaklı olduğu, verileri bütüncül hemşirelik bakımını sağlayacak şekilde değerlendiremedikleri belirlenmiştir. Benzer olarak yapılan çalışmalarda hemşirelik öğrencilerinin en çok zorluğu hemşirelik tanısının belirlenmesi aşamasında yaşadığı (Uysal vd., 2016; Taşkın Yılmaz vd., 2015; Sü, 2017), etiyolojik faktörlerle birlikte tanıyı doğru belirleyebilen öğrenci oranının düşük düzeyde olduğu (Güner ve Terakye, 2000) ve öğrencilerin hemşirelik tanılarını belirlemede sorun yaşadığı (Keski ve Karadağ, 2010) belirtilmiştir. Bu sonuçlar bulgumuzu destekler niteliktedir.

Çalışmada hemşirelik mesleğini isteyerek seçen ve hemşirelik sürecinin gerekliliğine inanan öğrencilerin hemşirelik tanılarını algılamaları daha düşük düzeyde bulundu. $\mathrm{Bu}$ öğrencilerin hemşirelik tanılarını algılamalarının yüksek olması beklenirken düşük çıkmasının iki nedeni olabilir. Birincisi klinik uygulama sırasında birebir hasta bakımına ve klinik rutinlerine çok zaman ayırmaları nedeniyle hemşirelik tanıları üzerinde çok düşünememeleri, ikincisi bütüncül hasta bakımı anlayışı doğrultusunda geniş kapsamlı veri toplamaları ve bu verileri bir araya getirmekte sıkıntı yaşamaları. Ayrıca çalışmada planlama ve değerlendirme basamağında sorun yaşayan öğrencilerin hemşirelik tanılarını algılamaları daha düşük bulundu. Bu bulgu hemşirelik tanısını daha kolay belirleyen öğrencilerin, hemşirelik tanılarını algılama düzeylerinin de daha iyi olduğu yönünde yorumlanabilir.

Çalışmada öğrencilerin mesleki değerleri arttıkça hemşirelik tanıları algılamalarının da arttığı bulundu. Literatürde hemşirelik öğrencilerinin mesleki değerleri ile hemşirelik tanılarını algılamaları arasındaki ilişkiyi inceleyen bir çalışmaya rastlanmamıştır. Hemşirelik müfredatında yer alan mesleki değerleri içeren dersler öğrencilerin karar verme ve karşılaştıkları problemler ile başa çıkmalarını sağlayan eleştirel düşünme yeteneklerini geliştirmektedir (Kaya vd., 2017). Hemşirelik öğrencileri eleştirel düşünmeyi gerektiren hemşirelik sürecini uygularken bu yeteneklerini sık sık kullanmaktadır (Yıldırım ve Özkahraman Koç, 2013). Bu konuda yapılan çalışmalarda hemşirelik süreci ve eleştirel düşünme ile ilgili ders alan öğrencilerin hemşirelik süreci hakkında daha olumlu algılar geliştirdikleri saptanmıştır (Tesoro, 2012; Victor-Chmil, 2013; Collins, 2013) Bu literatür bilgisi doğrultusunda mesleki değerleri yüksek olan örnekleme dahil edilen öğrencilerin, eleştirel düşünme yeteneklerinin gelişmiş olduğunu ve bu yeteneklerini hasta bakımına olumlu olarak yansıttıklarını düşünmekteyiz.

\section{SONUÇ VE ÖNERÍLER}

Hemşirelik öğrencilerinin mesleki değerlerinin iyi düzeyde olduğu, hemşirelik tanılarını algılamalarının orta düzeyde olduğu saptandı. Ayrıca hemşirelik tanılarını algılamanın mesleği isteyerek seçen, hemşirelik sürecinin gerekliliğine inanan ve planlama, değerlendirme basamaklarında zorluk yaşayan öğrencilerde daha düşük olduğu sonucuna ulaşıldı. Bu sonuçlar doğrultusunda hemşirelik müfredatında mesleki değerlere ve hemşirelik sürecine daha çok yer verilmesi, hemşirelik tanısı belirleme ile ilgili klinik uygulama sırasında daha çok vaka tartışması 
yapılması ve daha büyük örneklem grubunda tanımlayıcı ve deneysel çalışmaların yapılması önerilmektedir.

\section{Çalışmanın Sınırlıııkları}

$\mathrm{Bu}$ çalışma tek bir hemşirelik fakültesinde yapıldığı için sonuçlar genellenemez. Ayrıca çalışmanın öz bildirime dayanması ve anketlere öğrencilerin olması gerektiği gibi cevap vermesi sınırlılıklar arasında yer almaktadir.

Teşekkür: Çalışmaya katılan bütün öğrencilere teşekkür ederiz.

\section{Finansal destek}

Finansal destek alınmamıştır.

\section{Çıkar Çatışması}

Herhangi bir çıkar çatışması yoktur.

\section{Yazarlık Katkıları}

Tasarım/Design: S.S., K.N.K.; Veri Toplama veya Veri Girişi Yapma/Data Collection or Processing: S.S.,

K.N.K.; Analiz ve Yorum/Analysis or Interpretation: S.S., K.N.K.; Literatür Tarama/Literature Search: S.S., K.N.K.; Yazma/Writing: S.S, KNK.

\section{KAYNAKÇA}

Akansel, N. Palloş, A. (2020) Hemşirelik öğrencilerinin bakım planı hazırlamada yaşadıkları güçlüklerin kök nedenlerinin incelenmesi. ACU Sağllk Bil Derg, 11(2), 269-275. https://doi.org/10.31067/0.2020.265 269

Akın Korhan, E., Hakverdioğlu Yönt, G., Ak B., Erdemir F. (2013) Hemşirelik tanılarını algılama ölçeğinin Türkçe geçerlik ve güvenirliği. Hemşirelikte Araştırma Geliştirme Dergisi, 15(3), 13-25. http://www.hemarge.org.tr/dergi/sayi/33

Akın Korhan, E., Hakverdoğlu Yönt, G., Demray, A., Akça, A., Eker, A. (2015). Yoğun bakım ünitesinde hemşirelik tanılarının belirlenmesi ve nanda tanılarına göre değerlendirilmesi. Düzce Üniversitesi Sağllk Bilimleri Enstitüsü Dergisi, 5(1), 16-21. https://dergipark.org.tr/tr/pub/duzcesbed/issue/4848/66641

Birol L. (2016). Hemşirelik süreci. Akademisyen kitapevi.

Caner N, Efe Y.S., Erdem E, Başdaş Ö., Bayat M., Yıldırım M. (2019) İntörn hemşirelerde mesleki değerler ve etik duyarlılık. Sağllk Bilimleri Dergisi, 28(3), 123-128. https://doi.org/10.34108/eujhs.553135

Collins, A. (2013) Effect of continuing nursing education on nurses' attitude toward and accuracy of nursing diagnosis. Int. J. Nurs. Knowl. 24 (3), 122-128. https://doi.org/10.1111/j.2047-3095.2013.01237.x

Çöplü, Mehtap \& Tekinsoy Kartın, Pınar. (2018) Professional self-concept and professional values of senior students of the nursing department. Nursing Ethics, 26(5), 1387-1397. https://doi.org/10.1177/0969733018761171

Dündar, T., Özsoy, S., Topbaş, B., Aksu, H. (2019) Hemşirelikte mesleki değerler ve etkileyen faktörler. EGEHFD, 35(1), 11 19. https://dergipark.org.tr/tr/pub/egehemsire/issue/44946/450870

Erden S., Deniz S., Arslan S., Yurtseven Ş. (2018) Hemşirelik öğrencilerinin cerrahi hastalıkları hemşireliği dersi uygulamalarında hemşirelik tanılarını belirleme düzeylerinin incelenmesi. Van Tlp Derg, 25(2), 108-112. https://www.vantipderg.org/jvi.aspx? un $=V T D-26213 \&$ volume $=25 \&$ issue $=2$

Geçkil, E., Ege, E., Akin, B., Göz, F. (2012) Turkish version of the revised nursing professional values scale: validity and reliability assessment. Japan journal of nursing science: JJNS, 9(2), 195-200. https://doi.org/10.1111/j.17427924.2011.00202.x

Güner P., Terakye G. (2000) Hemşirelik yüksekokulları son sınıf öğrencilerinin hemşirelik tanılarını belirleyebilme düzeyleri. C.Ü. Hemşirelik Yüksekokulu Dergisi, 4 (1), 9-15.

Lacobucci, T. A., Daly, B. J., Lindell, D., Griffin, M. Q. (2013) Professional values, self-esteem, and ethical confidence of baccalaureate nursing students. Nursing ethics, 20(4), 479-490. https://doi.org/10.1177/0969733012458608

Lin, Y. H., Wang, L. S. (2010) A Chinese version of the revised Nurses Professional Values Scale: reliability and validity assessment. Nurse education today, 30(6), 492-498. https://doi.org/10.1016/j.nedt.2009.10.016

Karaca T., Aslan S. (2018) Effect of 'nursing terminologies and classifications' course on nursing students' perception of nursing diagnosis. Nurse Educ Today, 67, 114-117. https://doi.org/10.1016/j.nedt.2018.05.011

Karadağl1, F. (2016) Hemşirelik öğrencilerinin profesyonel değer algıları ve etkileyen faktörler. Mersin Üniversitesi Sağllk Bilimleri Dergisi, 9(2), 81-91. https://dergipark.org.tr/tr/pub/mersinsbd/issue/24537/259940 
Kaya, H., Babadağ K., Yeşiltepe Kaçar G., Uygur E. (2010) Nurses’ nursing model / theory, nursing process, and classification systems know and 1mplication status. Journal of Maltepe University Nursing Science and Art, 3(3), 24-33. https://www.researchgate.net/publication/235223634

Kaya, H., Işık, B., Senyuva, E., Kaya, N. (2012) Nursing students' individual and professional values. Anatolian Journal of Nursing and Health Sciences, 15, 18-26. https://www.researchgate.net/publication/235223309

Kaya H., Işik B., Şenyuva E., Kaya N. (2017) Personal and professional values held by baccalaureate nursing students. Nurs Ethics, 24(6):716-731. https://doi.org/10.1177/0969733015624488

Keski, Ç. ve Karadağ, A. (2010) Hemşirelik Son Sınıf Öğrencilerinin Hemşirelik Süreci Hakkındaki Bilgi Düzeylerinin İncelenmesi. Hemşirelikte Araştırma Geliştirme Dergisi, $\quad$ (1), 52. https://dergipark.org.tr/tr/pub/hemarge/issue/52707/695098

Kundakçı G., Gümüş A., Yılmaz M. (2018) Hemşirelik bölümü son sınıf öğrencilerinin değer tercihleri ile mesleki değerleri arasındaki ilişkinin incelenmesi. Uluslararası Hakemli Hemşirelik Araştırmaları Dergisi, 12, 82-98. https://www.researchgate.net/publication/324763928

Moon, S., Kim, D.H., Kim, E.J., Lee, S. (2014) Evaluation of the validity and reliability of korean version of the nursing professional values scale-revised. Nurse Education Today, 14, 325-350. https://doi.org/10.1016/j.nedt.2013.06.014

North American Nursing Diagnosis Association (NANDA-I), (2019). Call For Particıpants: Expert Clinıcal Advisory Panel For The Diagnosis Development Committee. Erişim adresi: https://nanda.org/call-for-participants-expert-clinicaladvisory-panel-for-the-diagnosis-development-committee/

Olmaz, D., Karakurt, P. (2019). Hemşirelerin Bakım Verirken Hemşirelik Sürecini Bilme ve Uygulama Durumları. Dokuz Eylül Üniversitesi Hemşirelik $\quad$ Fakültesi $\quad$ Elektronik $\quad$ Dergisi, $\quad 12(1), \quad 3-14$. https://dergipark.org.tr/tr/pub/deuhfed/issue/53195/705896

Orkun N., Çınar Yücel Ş. (2017) Hemşirelik fakültesi öğrencilerinin rahatta (konforda) bozulma hemşirelik tanısını kullanma durumlar1. HSP, 4 (3), 162-170. DOI: 10.17681/hsp.288841

Paslı Gürdoğan, E., Aksoy B., Kınıcı E. (2018) Hemşirelik öğrencilerinin etik duyarlılık düzeyleri ve mesleki değerler ile ilişkisi. Journal of Health and Nursing Management, 5(3), 147-154. DOI: 10.5222/SHYD.2018.147

Sü, S. (2017) Nursing students' opinions regarding the nursing process. International Journal of Humanities and Social Science Invention, 6(5), 10-14. https://www.semanticscholar.org/feed/create

Taskin Yilmaz, F., Sabanciogullari S., Aldemir K. (2015) The opinions of nursing students regarding the nursing process and their levels of proficiency in Turkey. Journal of Caring Sciences, 4(4), 265-275. doi:10.15171/jcs.2015.027

Tesoro, M. (2012) Effects of using developing nurses' thinking model on accuracy of nursing diagnosis. J. Nurs. Educ. 51, 436-443. DOI: 10.3928 /01484834-20120615-01

Uysal N., Gürol Arslan G., Yılmaz İ., Yetkin Alp F. (2016). Hemşirelik ikinci sınıf öğrencilerinin bakım planlarındaki hemşirelik tanıları ve verilerin analizi. CBU-SBED Celal Bayar Üniversitesi, Sağllk Bilimleri Enstitüsü Dergisi, 3(1):13943. https://dergipark.org.tr/tr/pub/cbusbed/issue/22332/239309

Victor-Chmil, J. (2013) Critical thinking versus clinical reasoning versus clinical judgment: differential diagnosis. Nurse Educ. 38 (1), 34-36. doi: 10.1097 / NNE.0b013e318276dfbe

Weis D., Schank JM. (2009) Development and psychometric evaluation of the nurses professional values scale revised. J Nurs Meas, 17:3221-231. doi: 10.1891 / 1061-3749.17.3.221

Yıldırım, B., Özkahraman Koç, Ş. (2013) Eleştirel düşünmeyi hemşirelik sürecinde uygulama. Ejovoc (Electronic Journal of Vocational Colleges), 3(3), 29-35. https://dergipark.org.tr/tr/pub/ejovoc/issue/5390/73096

Zengin M., Yayan E., Yıldırım N., Akın E., Avşar Ö., Mamiş E. (2018). Pediatri Hemşirelerinin Profesyonel Değerlerinin Profesyonel Tutumlarına Etkisi. Sağllk Bilimleri ve Meslekleri Dergisi. 10.17681/hsp.324725. DOI: https://doi.org/10.17681/hsp.324725 


\section{EXTENDED ABSTRACT}

Introduction: Nursing students should act with professional values rather than personal values when providing care to patients, defending their behaviour and attitude, explaining their reasons and making decisions against ethical dilemmas (Arkan et al., 2017). One of the situations where nursing students use their professional values is the nursing process. The nursing process consists of five stages: data collection, nursing diagnosis, identification of outcome criteria, planning/implementation and evaluation (Özer and Kuzu, 2006). Making correct nursing diagnoses allows patients to receive high quality nursing care. This is achieved by implementing the nursing process stages correctly and in full (Uysal et al.2016).

The study which was conducted to investigate the relationship between nursing students' professional values and their perception of nursing diagnoses intended to find answers to the following questions:

1. What is the level of professional values of nursing students?

2. What is the level of nursing students' perception of nursing diagnoses?

3. Do sociodemographic characteristics of nursing students affect their level of professional values and the level of perception of diagnoses?

4. Is there any relationship between nursing students' professional values and perception of nursing diagnoses?

Materials and Methods: The sample of this descriptive study consisted of 282 students in the nursing department of a state university in Turkey. Data was collected with the Socio-Demographic Characteristics Questionnaire, Nurses Professional Values Scale (NPVS) and Nursing Diagnoses Perception Scale (NDPS). The approval of the Ethics Committee and the institutional approval was obtained to conduct this study. Data was analysed with the SPSS program. Number, percentage, standard deviation, Student T test, Mann-Whitney U test, Kruskal Wallis Test and Pearson correlation analysis were used to analyse the data.

Findings: In the study $72.4 \%$ of the students was 21 years or younger and $25.2 \%$ of the students were in their third year. The study found that $72 . \%$ of the students willingly chose nursing as a career, $96.1 \%$ believed that nursing process is necessary and they experienced the least difficulty in the evaluation stage with $8.5 \%$. The mean score of the students in the NPVS was $100.99 \pm 17.86$; there was no statistically significant difference between the scale scores and the variables of the students' age, gender, social class, whether they believed in the necessity of nursing process, willingly chose nursing as a career and the stage where they experience difficulty $(\mathrm{p}>0.05)$. The mean score of the students in the NDPS was $2.39 \pm 0.34$; there was a statistically significant difference between the students' NDPS mean score and the variables of age, gender, social class, whether they believe in the necessity of nursing process, willingly choosing nursing as a career and the stage they experience difficulty ( $\mathrm{p}<0.05$ ). There was a positive statistically highly significant relationship between NPVS and NDPS scores of the students ( $\mathrm{p}<0.05$ ).

Discussion: Our study found that the students had high level of professional values. Similarly, the mean score of nursing students' professional values was $100.00 \pm 15.61$ in the study of Lin and Wang (2010); $101.4 \pm 12.7$ in the study of Lacobucci, Daly, Lindell and Griffin (2013); the mean score of intern nursing students' professional values was $100.53 \pm 15.80$ in the study of Caner et. al. (2019); $105.36 \pm 14.24$ in the study of Arkan et. al. (2019) and the mean score of final year nursing students' professional values was $102.88 \pm 15.67$ in the study of Kundakçı, Gümüş and Yılmaz (2018). In Geçkil et. al. study (2012)

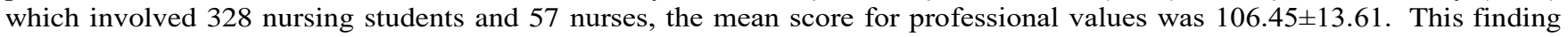
could be positively interpreted that students whose professional values improve during nursing education would reflect these in patient care in the future.

Our study found that nursing students' mean score in the perception of nursing diagnoses was at moderate level. Limited number of studies that investigate nursing students' perception of nursing diagnoses was found in the literature. Similar to our study, the mean score for the perception of nursing diagnoses was $2.44 \pm 0.44$ in the study of Karaca and Aslan (2018) and 3.09 \pm 0.63 in the study of Halverson et al. (2011). Similarly, studies in the literature found that the biggest difficulty experienced by nursing students is to make nursing diagnoses (Uysal vd, 2016; Taşkın Yılmaz et al. 2015; Sü, 2017), that the percentage of student who make correct diagnoses with etiological factors is low (Güner and Terakye 2000) and nursing students have difficulty in making nursing diagnoses (Keski and Karadağ, 2010). These results tend to support our finding.

This study found that as nursing students' professional values increase, their perception of nursing diagnoses also increases. No study which investigates the relationship between nursing students' professional values and perception of nursing diagnoses was found in the literature. Courses in the nursing curriculum, which include professional values improve critical thinking skills of the students allowing them making better decisions and dealing better with problems (Kaya et al., 2017). Nursing students often use these skills during the nursing process which require critical thinking (Yıldırım and Özkahraman Koç, 2013). Studies on this subject have found that students who take courses on nursing process and critical thinking have more positive perceptions about the nursing process (Tesoro, 2012; Victor-Chmil, 2013; Collins, 2013).

Conclusion and Suggestions: The study found that professional values of nursing students were at a good level; they had a moderate level of perception of nursing diagnoses and with the increasing nursing students' professional values, their level of perception of nursing diagnoses also increased. Furthermore students who willingly chose nursing as a career, believed in the necessity of nursing process and who had difficulties in planning and evaluation stages had lower level of perception of nursing diagnoses. Based on the above mentioned data; it is recommended that professional values and nursing process are included more in the nursing curriculum, more case discussions are done during clinical practice for nursing diagnoses and descriptive and experimental studies with bigger sample groups are conducted. 